\title{
Monitoring Kegagalan Sequence Flashing Lighting Runway 28 Menggunakan Fiber Optic Berbasis Microcontroller di Bandar Udara Internasional Juanda Surabaya
}

\author{
Hartono \\ Wasito Utomo \\ Politeknik Penerbangan Surabaya \\ Jl. Jemur Andayani I/73 Surabaya \\ Email : hartono.subawi@yahoo.co.id
}

\begin{abstract}
Abstrak
Rancangan ini bertujuan untuk mempermudah teknisi dalam melakukan monitoring sequence flashing lighting di bandara internasional Juanda, karena letak sequence flashing lighting yang jaraknya empat kilometer dari power house dan lokasinya yang sulit dijangkau terutama sequence flashing lighting runway 28 yang berada di tambak-tambak warga. Penelitian ini menggunakan microcontroller sebagai media kontrol dan kabel fiber optic sebagai media komunikasi, untuk mendeteksi nilai kegagalan dari lampu tersebut menggunakan sensor arus ACS712, metode untuk tampilan hasil monitoring menggunakan visual basic yang akan ditampilkan di komputer atau personal computer. Sedangkan untuk komunikasi antara personal computer dengan microcontroller menggunakan kabel UTP atau ethernet dengan dukungan ethernet media converterto serial. Hasil penelitian menunjukan untuk monitoring nyala dan mati sequence flashing lighting dapat menggunakan personal computer sehingga dengan metode ini kinerja teknisi menjadi lebih cepat dan efisien.
\end{abstract}

Kata kunci : sequence flashing lighting, microcontroller, fiber optic, ACS712, visual basic.

\section{Latar Belakang Masalah}

Sistem lampu sequence flashing adalah berupa susunan lampu yang berguna untuk memandu penerbang melakukan pendekatan ke runway dalam proses pendaratan. Dengan melihat rambu ini, penerbang akan mengetahui apakah pesawat sudah sejalur dengan runway ataukah belum. Dengan demikian, bila pesawat belum sejalur dengan runway atau centre runway maka tindakan penerbang adalah menyesuaikan supaya pesawat sejalur dengan runway. Sequence Flashing Lighting terletak di perpanjangan ujung runway. Rambu ini memancarkan cahaya yang berwarna puth secara berurutan mulai dari awal sampai akhir lampu sesuai dengan settingan modul lampu tersebut.

Bandar Udara Juanda konfigurasi lampu sequence mengikuti konfigurasi lampu approach yaitu dengan menggunakan PALS (Precision Approach Lighting Sysstem) dengan kategori I. . Berikut adealah gambar konfigurasi berbagai sistem lampu apprach, mulai dari yang simple, kategori I dan kategori II dan III. (ICAOAnnex 14, Volume I, Juli 1999).

Sistem pendekatan pencahayan sedehana (Simple Approach Lighting System) dimulai 500 meter sebelum landasan pacu ambang batas. Di Bandara-bandara Inggris menggunakan sistem Calvert, dimana lampu-lampu approach dipasang $900 \mathrm{~m}$ sebelum landasan pacu ambang batas. 


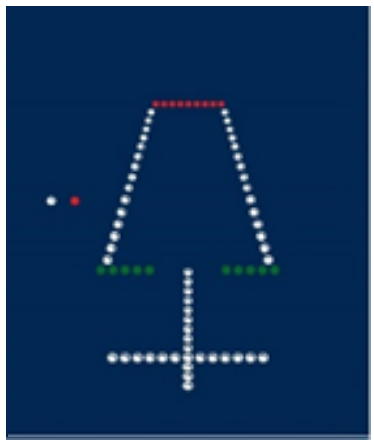



(b)



(c)

Gambar 1(a) Simple approach and Runway lighting system (b) Approach and runway lighting Typical cat I system showing Take-off starter extension and Stopway lighting dan (c) Approach and runway lighting Typical cat II or cat III system

\section{METODOLOGI PENELITIAN}

Proses monitoring ini sepenuhnya dapat dilakukan di tempat yang dekat dengan power house. Saat lampu sequence flashing menyala, artinya ada arus yang menuju ke beban, arus ini yang dibaca oleh sensor arus. Kemudian, arduino mengirimkan perintah dan selanjutnya hasil perintah tersebut ditampilkan dalam sebuah layar komputer. Proses monitoring ini diharapkan dapat mempermudah teknisi dalam mengontrol lampu sequence flashing yang berada di bandara Juanda. Kondisi yang diinginkan oleh penulis dapat dilihat pada gambar konsep rancangan dan blok diagram dibawah ini :

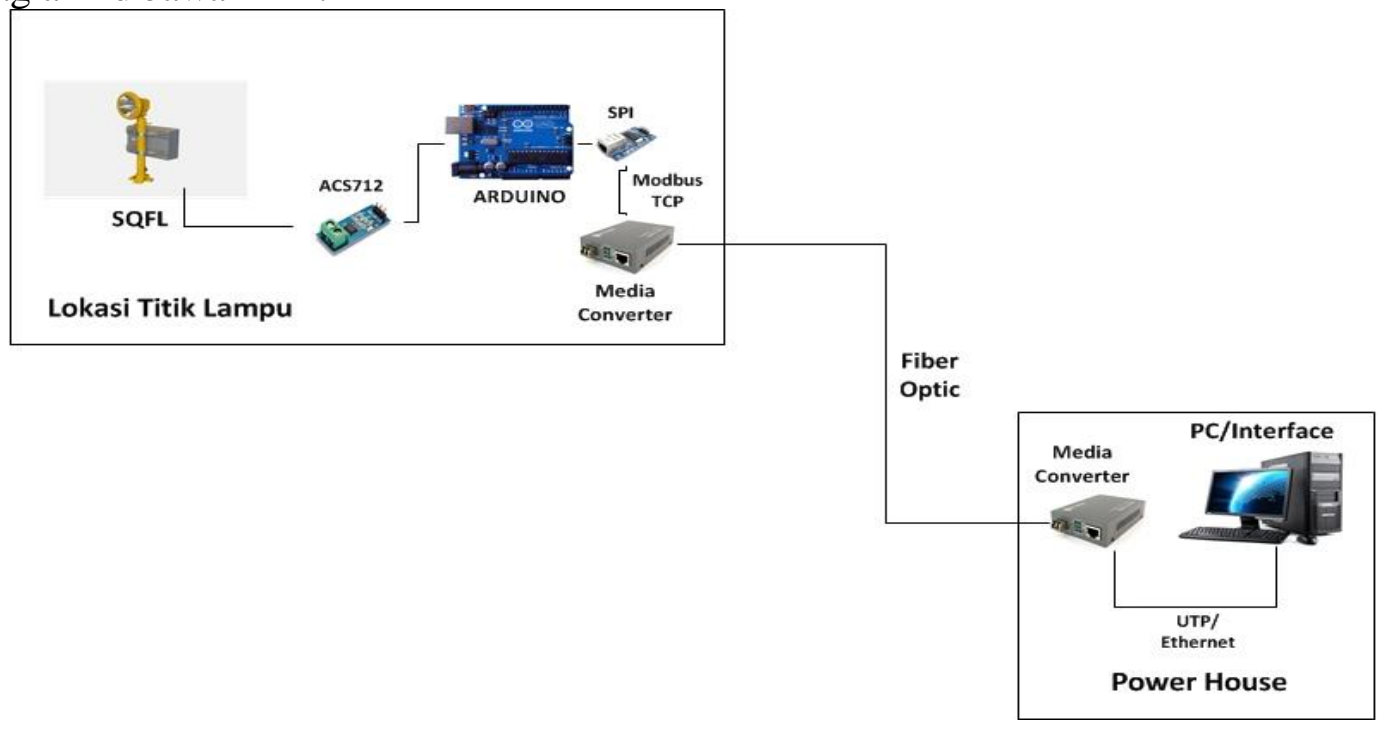

Gambar 2. Konsep Rancangan 


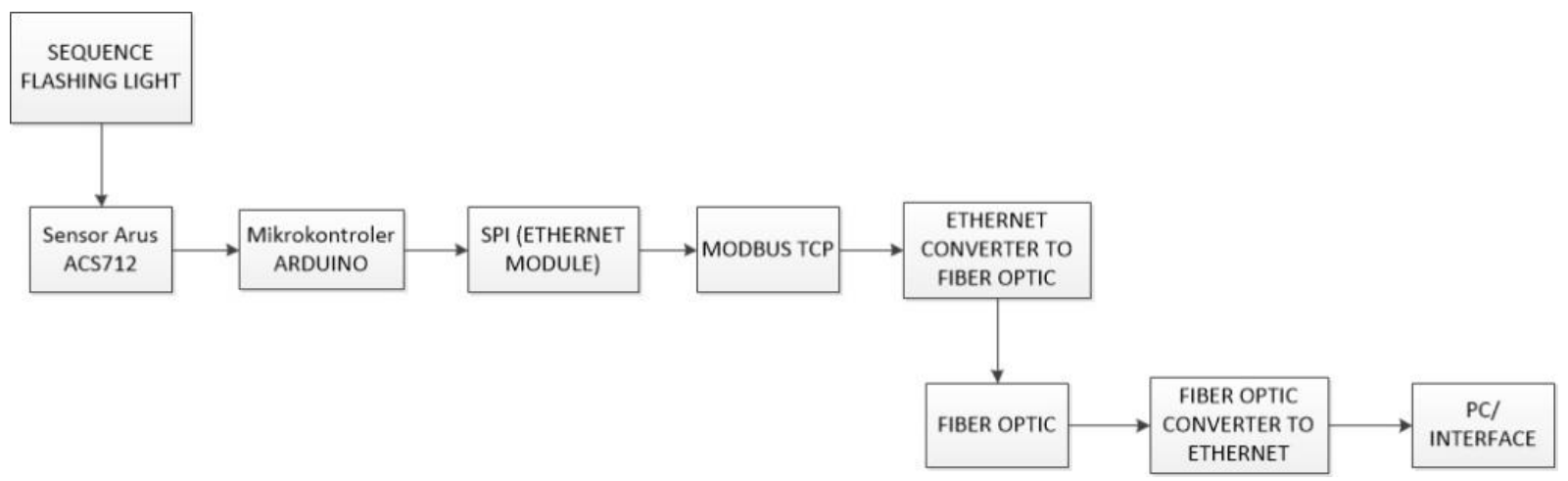

Gambar 3. Blok Diagram Sistem

Gambar blok diagram diatas menjelaskan bagaimana monitoring lampu sequence flashing dengan menggunakan sensor arus ACS 712. Dengan proses diagram seperti ini, memiliki keuntungan lebih yaitu apabila salah satu lampu sequence flashing tersebut tidak berfungsi dengan baik sesuai nilai arus yang seharusnya menuju beban, maka dapat diketahui lampu manakah yang tidak berfungsi dan monitoring dapat dilakukan tanpa menuju ke tempat lampu tersebut berada. Dengan demikian akan mempermudah dalam pengontrolan maupun dalam monitoringnya.

Secara keseluruhan sistem monitoring yang diinginkan yaitu monitoring dapat dilakukan secara komputerisasi. Komputerisasi disini yaitu dengan kata lain menggunakan tampilan interface, berupa tampilan nilai arus pada beban dan kondisi lampu menggunakan sensor arus ACS 712. Ouput dari sensor arus tadi kemudian dibaca oleh microcontroller ATMega 328 menggunakan pembacaan Analog to Digital Converter $(A D C)$. Setelah pembacaan $A D C$, hasil dari pembacaan $A D C$ selanjutnya dikirimkan menuju microcontroller ATMega 328 dan diolah sehingga dapat ditampilkan pada personal computer secara digital. Di Bandara Juanda, lampu sequence flashing yang digunakan memiliki daya sebesar $120 \mathrm{~W}$ dengan tegangan kerja sebesar 220 VAC. Itu artinya, untuk satu lampu sequence flashing, nilai arusnya sekitar 0,68 Ampere.

Apabila hasil pembacaan nilai arus pada setiap lampu sequence flashing tidak sesuai dengan nilai tadi, maka teknisi dapat secara langsung memastikan lampu mana yang tidak beroperasi dengan baik dan dapat menggantinya dengan lampu sequence flashing yang baru. Sensor arus ACS 712 yang digunakan memiliki kapasitas arus maksimal sebesar $5 \mathrm{~A}$, hal ini telah memenuhi kriteria dari arus minimal yang dilewati yaitu sebesar 0,68 A untuk setiap lampu sequence flashing. Pada kenyataannya, jarak antara lampu sequence flashingdengan pusat kontrol sejauh 4 $\mathrm{km}$. 


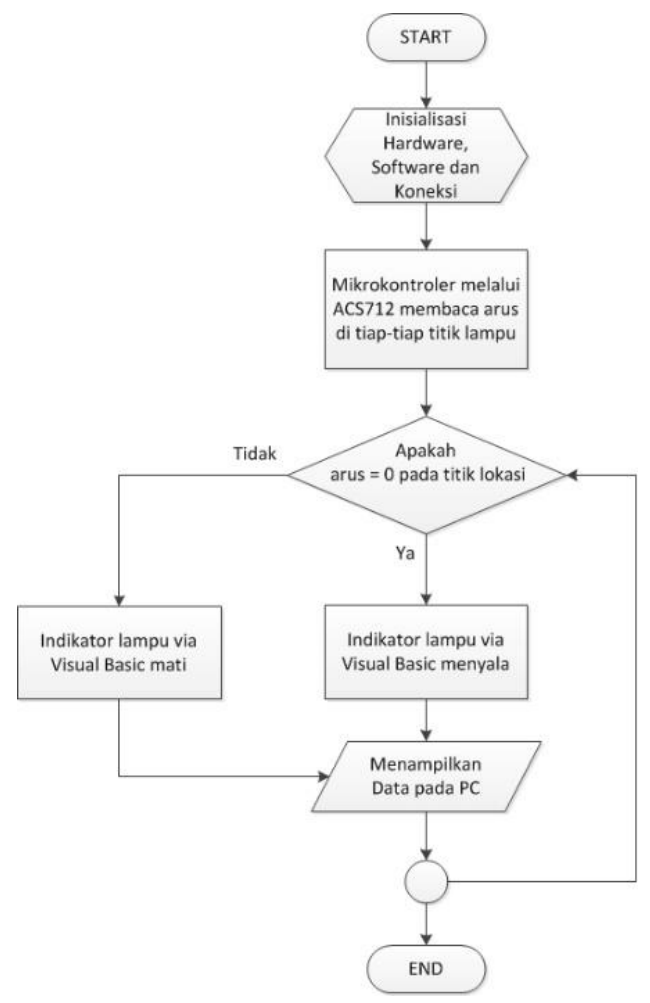

Gambar 4.Flow ChartSistem

\section{HASIL DAN PEMBAHASAN}

Perangkat Lunak dan Aplikasi Pemrograman

Program Perangkat Lunak Arduino Uno

Berikut adalah bahasa pemrograman arduino uno keseluruhan yang digunakan penulis dalam pembuatan alat tersebut :

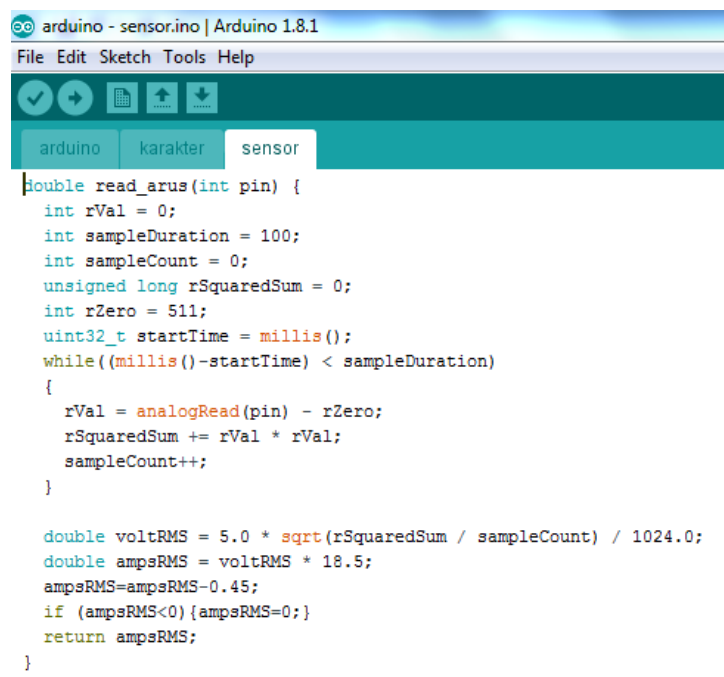

Gambar 5. Bahasa Pemrograman ACS 712

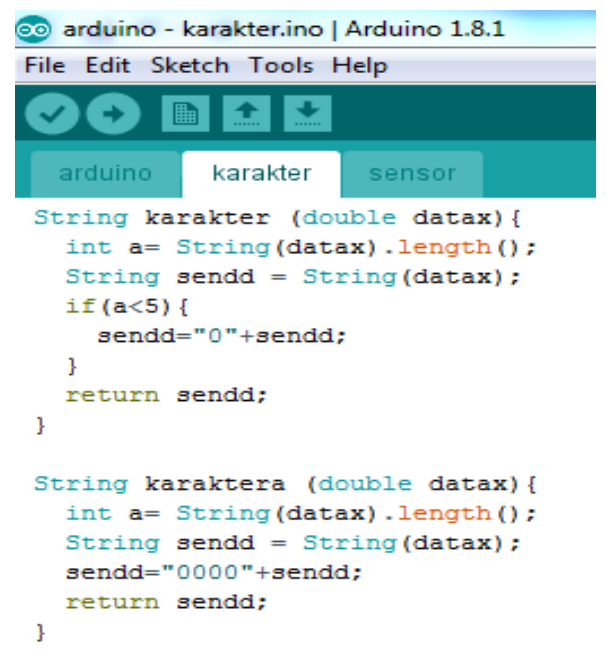

Gambar 6. Bahasa Pemrograman Flashing Lamp 


\section{Interface Perangkat Lunak Visual Basic}

Pada pengujian ini dapat dilihat bahwa tampilan software dapat berjalan baik. Jika tanda koneksi pada pojok kiri atas sudah memperlihatkan tanda connected dan arus yang muncul dalam detail properti sudah membaca nilai arus di tiap-tiap beban berarti alat berjalan dengan baik.

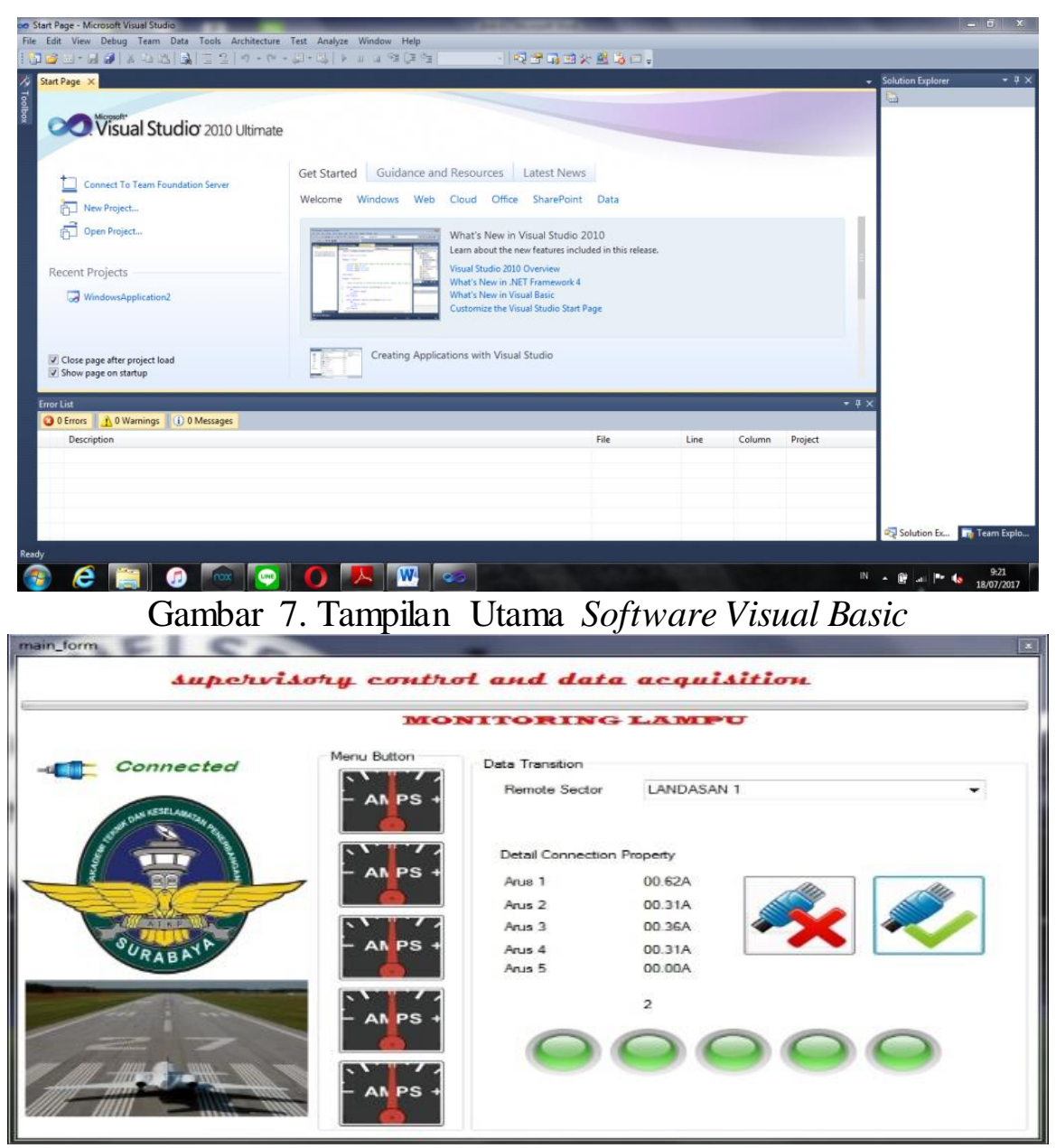

Gambar 8. Pengujian Tampilan Visual Basic

Berikut adalah beberapa bahasa pemrograman dari softwarevisual basic yang digunakan penulis.

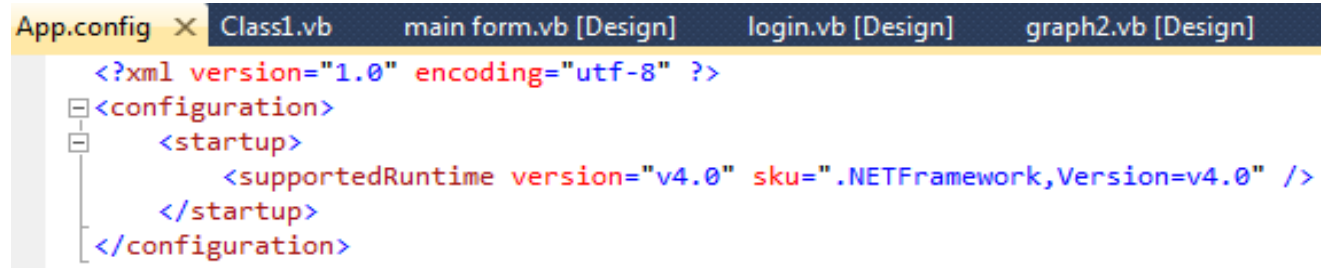

Gambar 9. Bahasa Pemrograman untuk Visual Basic 


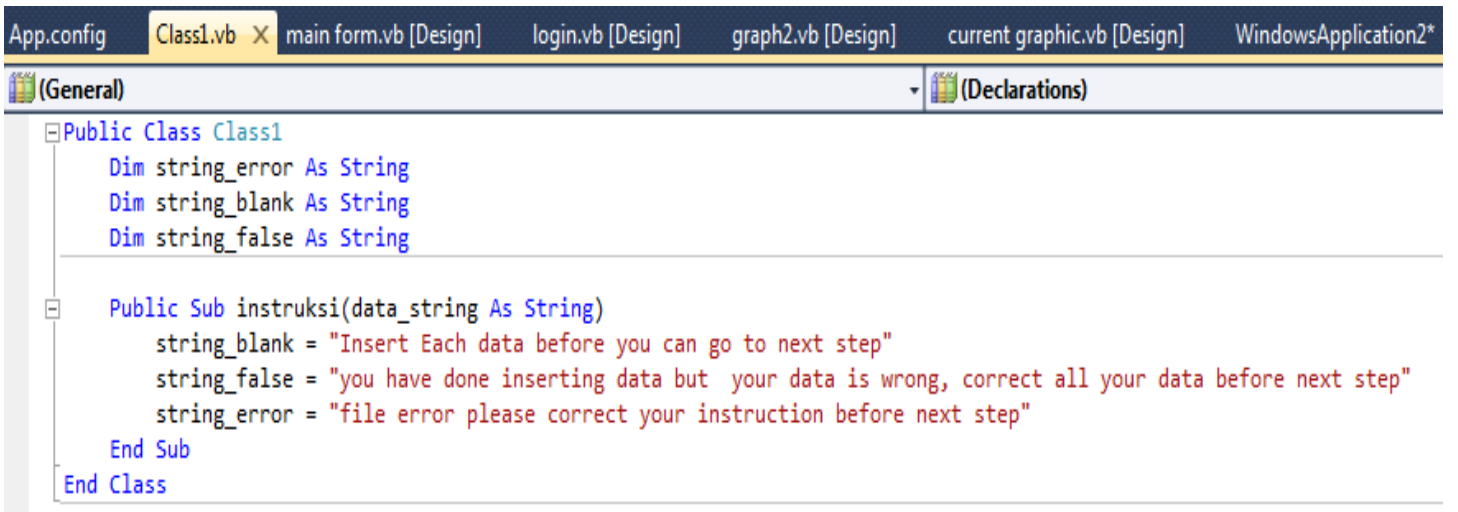

Gambar 10. Bahasa Pemrograman atau coding Visual Basic untuk Indikator Lampu

\section{Sistem Alat Keseluruhan}

Dari pengujian di tiap-tiap rangkaian komponen dan pengujian software tersebut diatas terbentuklah suatu rancangan alat monitoring kegagalan sequence flashing light dengan hasil pengujian sebagai berikut :

Memasukkan bahasa pemrograman atau coding seluruh sistem pada aplikasi atau softwarearduino.

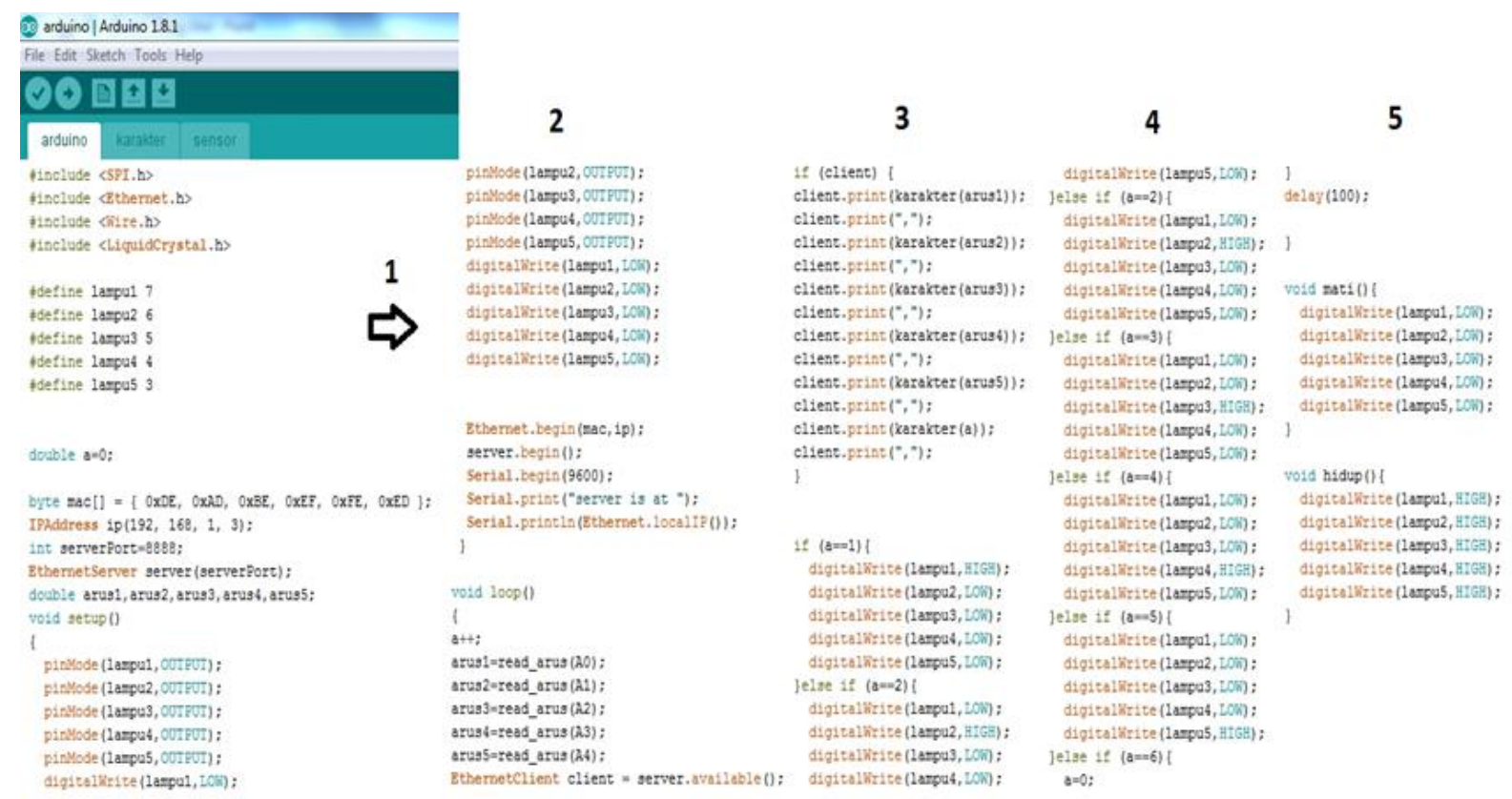

\section{Gambar 11. Bahasa Pemrograman SoftwareArduino untuk Sistem Keseluruhan}

\section{Kesimpulan}

Dengan melakukan perancangan monitoring lampu sequence flashing di bandara Juanda, penulis memiliki beberapa kesimpulan yaitu : 
1. Kita dapat memonitoring lampu sequence flashing di bandara Juanda secara real time dan mengetahui secara pasti lampu manakah yang tidak berfungsi dengan baik tanpa harus melakukan kontrol secara langsung ke tempat lampu sequence flashing berada.

2. Monitoring lampu sequence flashing juga dapat dilakukan dengan menggunakan visualisasi dari software visual basic yang langsung dapat menampilkan nilai arus pada masing-masing lampu.

3. Informasi data mengenai berfungsi atau tidaknya lampu sequence flashing dapat dikirim dengan sangat cepat melalui komunikasi fiber optic meskipun dengan jarak 4 kilometer.

4. Dapat dengan mudah mengetahui kerusakan pada lampu sequence flashing tanpa harus turun langsung kelapangan untuk mengecek di tiap-tiap lampu.

\section{DAFTAR PUSTAKA}

Dalam Visual Aids Handbook, CAP 637.

Dipetik 2 14, 2017, dari Ethernet Module System: http//support@ innovativeelectronics.com Dipetik 2 13, 2017, dari www.arduino.cc: http:/www.arduino.cc

Datasheet.Atmega328/P. (2016).

Datasheet.ACS712.

Aerodrome. Manual of Standard CASR 139 Volume 1 .

Aerodrome. ICAO ANNEX 14 Volume 1.

Bejo, A. (2008). Rahasia Kemudahan Bahasa. Yogyakarta: Graha Ilmu.

Blocher, R. (2004). Dasar Elektronika. Yogyakarta: Andi.

Hantoro, G. D. (2010). Fiber Optic. Yogyakarta: Graha Ilmu.

Honeywell. Dalam Manual Of Book ASL 40 Approach Sequence Flash Light with SFU 40 Pulse Generator.

Ibrahim, K. (1996). Prinsip Dasar Elektronika. Jakarta: PT. Elex Media Komputindo.

Kadir, A. (2012). Panduan Praktis Mempelajari Aplikasi Microcontroller. Yogyakarta: Andi.

Kuncara, Purba. (2013). Fiber Optics Technicians. Bandung: Informatika.

Marta Dinata, Yuwono. (2016). Arduino Itu Pintar. Surabaya: Gramedia.

Oliviero, Andrew and Woodward,Bill. (2009). Cabling. Sybex.

Winoto, Ardi. (2008). Mikrokontroler AVR ATmega dan Pemrogramannya. Bandung: Informatika. 